\title{
A Política de Educação Profissional e a Mercantilização da Educação: O Público e o Privado na Execução do Pronatec
}

\author{
Policy of Professional Education and Education of Merchantability: Public \\ and Private in Implementing Pronatec
}

\section{Política de Educación Profesional y Educación de Comercialización: Público y Privado en la Aplicación Pronatec}

\author{
Maria Luzirene Oliveira do Nascimento' \\ ' Mestranda do Programa de Pós Graduação em Educação da Universidade Federal do Piauí \\ (UFPI) - Teresina - PI - Brasil. Email luzirene oliveira89@outlook.com
}

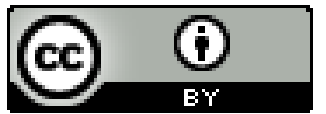

Educação: teoria e prática, Rio Claro, SP, Brasil - eISSN: 1981-8106

Está licenciada sob Licença Creative Common

\section{Resumo:}

O presente trabalho é dedicado à análise da implantação do Programa Nacional de Acesso ao Ensino Técnico e Emprego (Pronatec), criado no Governo Dilma (2011-2014), que integra as ações da política de Educação Profissional. Abordamos a relação entre o público e o privado que permeia essa proposta, vez que, o referido programa tem sido executado pela União em parceria com os Estados, Municípios e setores da iniciativa privada. Desta feita, torna-se pertinente a discussão acerca da privatização da educação no âmbito da política de Educação Profissional, ao considerarmos que o setor privado recebe recursos públicos para promoção de política de formação para o mercado de trabalho. No âmbito desse debate destacamos a Bolsa-Formação e o Fies Técnico empresa, que possibilita a execução do ensino técnico por empresas e o Sistema $\mathrm{S}$ com o repasse de recursos públicos para a oferta de cursos técnico. A articulação do público-privado na execução do Pronatec suscita questionamentos pertinentes à análise das contradições desse programa com vistas a compreender o caráter do financiamento público da oferta de educação profissional pela rede privada, no que concerne as seguintes indagações: o Pronatec é uma proposta que constitui uma modalidade de privatização da educação? $\mathrm{O}$ Pronatec é restrito a formar mão de obra para o mercado de trabalho, numa perspectiva mercantilista?A pesquisa tem caráter documental e bibliográfico. Utilizamos registro e 
sistematização de dados e informações colocadas em análise vez que a pesquisa documental se constitui como técnica de identificação, levantamento, exploração de fontes do objeto pesquisado no Estado do Piauí.

Palavras-chave: Pronatec; Privatização; Educação Profissional.

\begin{abstract}
The present work is devoted to analysis of the implementation of the National Program for Access to Technical Education and Employment (Pronatec), created in Dilma Government (2011-2014), which integrates the actions of Vocational Education policy. Deals with the relationship between the public and private that permeates this proposal, since, this program has been run by the Union in partnership with the states, municipalities and sectors of private enterprise. This time, it is pertinent to the discussion about the privatization of education in the context of Vocational Education policy, when we consider that the private sector receives public funds for training policy of promotion to the labor market. Within this debate highlight the Exchange Training and Technical Fies company that makes execution of technical education by businesses and the $S$ system with the transfer of public resources for the provision of technical courses. The joint public-private in the implementation of Pronatec raises questions relevant to the analysis of the contradictions of this program in order to understand the public funding of the character of the delivery of education by private network, as regards the following questions: Pronatec is a proposal that is a form of privatization of education? The Pronatec is restricted to form labor for the labor market, a mercantilist perspective? Research has documentary and bibliographic character. For use registration and systematization of data and information placed under review, as the documentary research is constituted as identification technique, survey, sources of exploitation of the researched object.
\end{abstract}

Keywords: Pronatec; Privatization; Professional Education.

\title{
Resumen
}

El presente trabajo está dedicado al análisis de la implementación del Programa Nacional de Acceso a la Educación Técnica y Empleo (Pronatec), creado en el gobierno Dilma (2011-2014), que integra las acciones de la política de enseñanza profesional. Se ocupa de la relación entre lo público y lo privado que se respira en esta propuesta, ya que, este programa ha sido dirigido por la Unión en colaboración con los estados, municipios y sectores de la empresa privada. Esta vez, es pertinente para el debate sobre la privatización de la educación en el contexto de la política de enseñanza profesional, si tenemos en cuenta que el sector privado recibe fondos públicos para la política de formación de la promoción en el mercado laboral. Dentro de este debate destacar la Formación y Fies Técnica compañía Exchange que hace que la ejecución de la educación técnica en las empresas y el sistema $S$ con la transferencia de recursos públicos para la prestación de cursos técnicos. El público-privada en la ejecución de Pronatec plantea cuestiones relevantes para el análisis de las contradicciones de este programa con el fin de entender la financiación pública del carácter de la prestación de la educación por la Educação: Teoria e Prática/ Rio Claro/ Vol. 25, n.50/ p. 562-575/ Set.-Dez. 2015. 
red privada, por lo que respecta a las siguientes preguntas: Pronatec es una propuesta que es una forma de privatización de la educación? El Pronatec está restringido para formar mano de obra para el mercado de trabajo, una perspectiva mercantilista? La investigación tiene carácter documental y bibliográfico. Para la autorización para uso y sistematización de los datos y la información puestos en examen, según la investigación documental se constituye como técnica de identificación, estudio, fuentes de la explotación del objeto investigado.

Palabras clave: Pronatec; La privatización; Educación Profesional.

\section{Introdução}

As políticas de Educação Profissional no Brasil têm sido bastante promissoras para as demandas do mundo do trabalho na sociabilidade do capital, tanto para formar mão de obra qualificada quanto para criar reservas de mão de obra para um mercado que não absorve todo o contingente de profissionais disponíveis, mesmo quando formados, especialmente no contexto do desemprego estrutural. Desde 2003, o governo federal tem investido veementemente nessa modalidade de educação, inclusive com reformas da política de educação profissional, mediante revogação de decretos, implementação de programas e expansão da oferta desta modalidade de ensino.

O presente trabalho é dedicado à análise da implementação do Programa Nacional de Acesso ao Ensino Técnico e Emprego (Pronatec), desenvolvido no Governo Dilma (2011-2014), problematizando a relação entre o público e o privado que permeia essa proposta, uma vez que este programa tem sido executado pela União em parceria com os estados, municípios e setores da iniciativa privada. Desta feita, torna-se pertinente a discussão acerca da privatização da Educação Profissional, pois o repasse de recursos públicos para o setor privado para a promoção de políticas de formação para o mercado de trabalho termina por beneficiar duplamente este setor.

O Pronatec foi instituído pela Lei ${ }^{\circ} 12.513 / 2011$, com a finalidade de ampliar a oferta de educação profissional e tecnológica, por meio de programas, projetos e ações de assistência técnica e financeira. Este programa tem apresentado um contraponto às reformas de Educação Profissional promovidas no Governo Lula, ao apontar para a formação meramente técnica, desvinculada de uma formação integral, contraditoriamente a perspectiva do Decreto $n^{\circ}$ 5.154/2004. Embora esse Decreto permita "variadas formas de organização da educação profissional técnica, desde a separação completa em relação ao ensino médio até a integração total" ele pretendeu resgatar a possibilidade de oferta integrada ao ensino médio, cassada durante o governo FHC com a promulgação do Decreto $\mathrm{n}^{\circ}$ 2.208/1997. Todavia o Pronatec enfraquece a proposição do referido Decreto 5154/2004 ao estimular e induzir a oferta da Educação Profissional desvinculada do ensino médio envolvendo, ainda, organicamente a iniciativa privada.

Este estudo, portanto, analisa o Pronatec executado na esfera de instituições privadas. A articulação do público-privado na execução do Pronatec suscita questionamentos pertinentes à análise das contradições desse programa com vistas a 
compreender o caráter do financiamento público da oferta de educação profissional pela rede privada, nos seguintes termos: o Pronatec é uma proposta que se constitui como uma modalidade de privatização da educação? O Pronatec é restrito a formar mão de obra para o mercado de trabalho, numa perspectiva mercantilista?

A pesquisa tem caráter documental e bibliográfico. A pesquisa documental é toda forma de registro e sistematização de dados, informações, colocando-os em condições de análise por parte do pesquisador (SEVERINO, 2007, p. 124). No caso estudado, a pesquisa documental se constitui como técnica de identificação, levantamento, exploração de fontes do objeto pesquisado, e traz dados pertinentes ao Estado do Piauí.

\section{A implementação do Pronatec: a relação público-privado na Educação Profissional}

A relação entre o público e o privado nas políticas educacionais marca, historicamente, a contradição entre a educação para uma emancipação humana (emancipadora) e a educação para o mercado de trabalho (mercantilista). No âmbito da Educação Profissional, as políticas destinadas a essa modalidade de ensino têm sido, predominantemente, voltadas à formação de mão de obra para o mercado, portanto aos interesses do capital. De acordo com Paro (2001, p.22) "quando se examina a prática e se analisa com frieza o que a escola procura fazer, na ação de seus professores e no atendimento às aspirações e expectativas de seus usuários, o que aparece sempre como perspectiva essencial é o mercado de trabalho", disto decorre a responsabilidade que é transferida para a educação de possibilitar mobilidade social e empregabilidade, principalmente no âmbito da Educação Profissional, porque diretamente relacionada à formação para o trabalho. Sob essa perspectiva Paiva (2002, p.59) nos esclarece que:

\footnotetext{
A "empregabilidade" converte-se, neste caso, num corolário dos conhecimentos, habilidades e esforço individual de adequação. Torna-se tarefa das instituições que oferecem educação tentar tornar sua clientela empregável, adequando seus cursos a demanda e incluindo na formação elementos subjetivos capazes de assegurar maior adesão dos quadros às instituições e seus objetivos. Digamos que a contração do mercado de trabalho aprofunda a subsunção do sistema educacional (e especialmente da educação profissional) aos requisitos do capital.
}

Na Educação Profissional temos presenciado a preocupação do Estado com a oferta dessa modalidade de ensino, expressa em investimentos de recursos em políticas voltadas à formação do trabalhador, inclusive em parceria com a esfera privada. Esta perspectiva contribui para a mercantilização da oferta da Educação Profissional, uma vez que, não sendo ofertada diretamente pela esfera pública, se constitui numa possibilidade de Educação: Teoria e Prática/ Rio Claro/ Vol. 25, n.50/ p. 562-575/ Set.-Dez. 2015. 
mercado educacional. De acordo com estudos da EPSJV/FioCruz (2014) "o Governo tem sido um importante incentivador dessas instituições através dos programas que subsidiam com recursos públicos a oferta privada de educação".

O Decreto 5.154/2004, promulgado no governo Lula da Silva, ainda permite variadas formas de oferta e organização da Educação Profissional, podendo ser ofertada também através de cursos técnicos aligeirados. Nesse contexto, é que o governo Dilma (2011 a 2014), dando continuidade ao projeto político de seu antecessor, cria o Pronatec, instituído pela lei 12.513/2011, oferta cursos técnicos desvinculados do ensino médio, com cursos que visam uma formação meramente técnica. No âmbito da gestão e do financiamento, a implantação do Pronatec possibilita a parceria entre o público e o privado. Quanto a estas parcerias a lei que regulamenta o Pronatec assegura que:

Art. 8o O Pronatec poderá ainda ser executado com a participação de entidades privadas sem fins lucrativos, devidamente habilitadas, mediante a celebração de convênio ou contrato, observada a obrigatoriedade de prestação de contas da aplicação dos recursos nos termos da legislação vigente. (BRASIL, 2011)

O Pronatec foi criado no referido governo com a finalidade de ampliar a oferta de educação profissional e tecnológica, por meio de programas, projetos e ações de assistência técnica e financeira.

Desta feita, ressaltamos o caráter da educação como possibilidade de formação de um capital humano para o mercado. Na definição de O' Connor (1977, p. 108) o capital humano faz parte de um capital social, e é uma forma de investimento que "compreende o ensino, os serviços administrativos e outros, em todos os níveis do sistema educativo e científico, e os serviços de pesquisa e desenvolvimento, dentro e fora da instituição educacional".

No entanto, as empresas veem a qualificação do trabalhador como dispendiosa, relegando essa tarefa ao sistema educacional, e quando se propõem a qualificar o trabalhador, necessitam de parcerias com o poder público, como por exemplo, o programa Escola na Fábrica ${ }^{1}$ que visa a expansão da rede de Educação Profissional tendo como local de formação a empresa privada. Para O'Connor isto ocorre porque:

No contexto de um mercado livre de trabalho nenhuma empresa, ramo de atividade ou grupo de interesses financeiros-industriais pode dar-se ao luxo de treinar sua própria força de trabalho, ou de canalizar lucros para o montante necessário de pesquisa e desenvolvimento. As patentes comportam uma certa proteção, mas não há garantias contra o fato dos empregados chaves de uma dada empresa procurarem posições em uma outra empresa ou em outros ramos. (O’CONNOR, 1997, p. 122)

Ou seja, a qualificação do trabalhador é vista como uma condição que deve atender as necessidades de mercado e das empresas, embora a Educação Profissional, historicamente, tenha se constituído uma modalidade de ensino de segundo plano nas

\footnotetext{
${ }^{1}$ Escola de Fábrica constitui-se em parceria com o Governo Federal com entidades públicas e privadas sem fins lucrativos (unidade gestora) na instalação de salas de aula em empresas para formar jovens profissionais. O programa foi instituído pela Lei no 11.180/2005 e foi incorporado ao PROJOVEM urbano. ( SOUSA, 2011)

Educação: Teoria e Prática/ Rio Claro/ Vol. 25, n.50/ p. 562-575/ Set.-Dez. 2015.
} 
políticas de governo, e protagonista da dualidade estrutural entre ensino técnico e propedêutico. Para Gentilli (1998) a teoria do capital humano no que concerne a relação entre trabalho e educação tomou "uma lógica econômica estritamente privada e guiada pela ênfase nas capacidades e competências que cada pessoa deve adquirir no mercado educacional para atingir uma melhor posição no mercado de trabalho" (GENTILLI, 1998, p. 81).

A educação é um meio de potencializar o capital humano para o trabalho, dessa forma o mercado de oferta de educação se torna um negócio lucrativo para o setor privado, multiplicam-se as oportunidades para formação de uma mão de obra necessária e excedente para o capital, e minimiza-se a responsabilidade do Estado com a oferta de educação pública, gratuita e de qualidade.

De acordo com Guimarães et al(2014), em estudo realizado pela Fiocruz aponta que:

Em dezembro de 2013, a Bolsa de Valores de São Paulo emitiu o informe 'Saraiva fecha parceria com Kroton para o Pronatec'. Segundo o texto, o objeto do contrato é o "fornecimento de conteúdo em 25 cursos ofertados pela Kroton Educacional S.A." no âmbito do Pronatec. No mesmo texto, informa-se que no segundo semestre de 2013 a Saraiva comprou a Editora Erica LTDA numa "transação" que "marcou sua entrada no mercado de conteúdo voltado para ensino técnico profissionalizante". (GUIMARÃES, 2014)

Outro setor que também executam o programa é o Sistema S. No âmbito do Estado do Piauí, nos dados disponibilizados pela Secretaria de Educação do Piauí SEDUC, as principais instituições que compõem o Sistema $S$ aparecem com maior número de vagas e oferta na modalidade Formação inicial continuada (FIC) e técnica no período de 2011 a 2013. Com destaque para o Serviço Nacional de Aprendizagem que em 2013 ofertou 8.879 vagas, concentrando o maior número de vagas dentre as instituições apresentadas no quadro abaixo.

Tabela 37: Dados PRONATEC no Piauí

\begin{tabular}{|c|c|c|c|c|c|c|c|c|c|}
\hline \multirow{3}{*}{ OFERTANTE } & \multirow{2}{*}{\multicolumn{3}{|c|}{ № de VAGAS }} & \multicolumn{6}{|c|}{ OFERTA } \\
\hline & & & & \multicolumn{2}{|c|}{2011} & \multicolumn{2}{|c|}{2012} & \multicolumn{2}{|c|}{2013} \\
\hline & 2011 & 2012 & 2013 & FIC & TEC & FIC & TÉC & FIC & TÉC \\
\hline $\begin{array}{l}\text { Serviço Nacional de Aprendizagem } \\
\text { Comercial-SENAC }\end{array}$ & 4084 & 9685 & 8879 & 36 & 09 & 21 & - & 332 & 44 \\
\hline $\begin{array}{l}\text { Serviço Nacional de Aprendizagem } \\
\text { Industrial-SENAl }\end{array}$ & 862 & 794 & 2042 & 09 & 02 & 21 & - & 118 & - \\
\hline Instituto Federal do Piauí - IFPI & 4186 & 5266 & 2561 & 46 & 11 & 36 & - & 27 & 14 \\
\hline $\begin{array}{l}\text { Serviço Nacional de Aprendizagem Rural } \\
\text { - SENAR }\end{array}$ & - & 240 & 750 & 10 & - & - & - & 50 & - \\
\hline
\end{tabular}

Educação: Teoria e Prática/ Rio Claro/ Vol. 25, n.50/ p. 562-575/ Set.-Dez. 2015. 


\begin{tabular}{|c|c|c|c|c|c|c|c|c|c|}
\hline $\begin{array}{l}\text { Serviço Nacional de Aprendizagem do } \\
\text { Transporte }\end{array}$ & - & - & 285 & & & & & 13 & - \\
\hline $\begin{array}{l}\text { Secretaria da Educação e Cultura do } \\
\text { Piauí }\end{array}$ & - & 880 & 2748 & - & 03 & - & - & - & 08 \\
\hline Colégio Agrícola de Bom Jesus & - & 820 & 2110 & 09 & 04 & - & - & 22 & 04 \\
\hline Colégio Agrícola de Floriano & - & 240 & 750 & 06 & - & - & - & 13 & 7 \\
\hline Colégio Agrícola de Teresina & - & 400 & 1183 & 10 & - & - & - & 17 & 6 \\
\hline TOTAL & 9.132 & 18.325 & 21.308 & 126 & 29 & 78 & - & 592 & 83 \\
\hline
\end{tabular}

Fonte: PRONATEC/SEDUC

Nesse quadro podemos constatar o crescimento do número de vagas desde 2011, ano da criação do programa, até 2013. Houve um crescimento da oferta em todas as instituições, de forma mais acentuada na modalidade de Formação Inicial e Continuada. Mas podemos observar que as instituições que compõem o Sistema S apresentam o maior número de vagas e de oferta, dentre todas as instituições, com exceção do SENAT (Sistema Nacional de Aprendizagem do Transporte), com um número de vagas e oferta menor do que o Instituto Federal do Piauí. Neste âmbito Guimarães et al (2014) em contribui para a análise de que :

Uma parte importante da rede privada de educação profissional instalada no Brasil integra o chamado Sistema $\mathrm{S}$ - composto por nove instituições, entre elas o Senai e o Senac - que forma uma polêmica à parte. Embora tenha gestão privada, o Sistema S é mantido com recursos chamados de parafiscais. Esses recursos são considerados públicos porque resultam de contribuições compulsórias das empresas, que, por sua vez, repassam essa despesa para o custo dos produtos, portanto, para o consumidor. Apesar disso, muitas instituições vinculadas a essa rede cobram pelos cursos que oferecem. A maior regulação sobre o Sistema $S$ é uma das frentes de atuação do MEC desde o governo Lula e, segundo Eliezer Pacheco, é também uma das prioridades do Pronatec. (GUIMARÃES, 2014 )

Os cursos do Pronatec ofertados pelo Senac (Sistema Nacional de Aprendizagem Comercial), por exemplo, são destinados a jovens ou adultos de baixa renda como qualificação para atender as exigências do mundo do trabalho. No caso do SENAC o público-alvo deve se enquadrar nos requisitos abaixo:

O Pronatec beneficia brasileiros jovens e adultos de baixo poder aquisitivo. A parceria do Governo Federal com o Senac possibilita às pessoas assistidas acesso a bolsas-formação. Há dois tipos: a bolsaformação estudante e a bolsa-formação trabalhador. O Senac poderá atender também aos beneficiários do Fundo de Financiamento Estudantil (Fies) Técnico, que provê linhas de crédito direto aos que já tenham concluído o ensino médio - em caráter individual (Fies Estudante) ou por meio de empresas que queiram qualificar seus empregados (Fies Empresa). (SENAC, 2014) 
São ofertados cursos na modalidade técnica como garçom, operador de câmera, agente de gestão de resíduos sólidos, técnico em podologia, dentre outros. Os beneficiários do Pronatec devem atender o perfil apresentado neste quadro:

\begin{tabular}{|l|}
\hline \multicolumn{1}{|c|}{ Beneficiário } \\
\hline Estudantes do Ensino Médio da rede pública, inclusive da educação de jovens e adultos. \\
\hline Trabalhadores, inclusive agricultores familiares, silvicultores, aquicultores, extrativistas e pescadores. \\
\hline Beneficiários de programas federais de transferência de renda ou pessoas inscritas no Cadúnico* \\
\hline Pessoas com deficiência \\
\hline Povos indígenas, comunidades quilombolas e outras comunidades tradicionais \\
\hline $\begin{array}{l}\text { Estudante que tenha cursado o ensino médio completo em escola da rede pública ou em instituições privadas na } \\
\text { condição de bolsista integral }\end{array}$ \\
\hline Desempregados \\
\hline Reservista das Forças Armadas (exército, Marinha e Aeronáutica) ou Atiradores de Tiros de Guerra \\
\hline *Cadastro Único para Programas Sociais. \\
Quadro retirado do documento Diretrizes: a participação do Senac no Pronatec, 2013. \\
\hline
\end{tabular}

Os dados apresentados sobre o Pronatec apresentam um cenário em que a qualificação do trabalhador está relacionada às transformações no mundo do trabalho advindas do processo de reestruturação da produção e mundialização do capital, que provocou uma constante necessidade de mão de obra, especializada e técnica.

A atenção despendida por instituições privadas para a execução de programas de Educação Profissional, especialmente o Pronatec, decorre da percepção de que a parceria com o Estado é uma possibilidade dessas instituições alargarem seu mercado de oferta e crescimento na educação privada. Para Teodoro (2014, p.6) isto é resultado do entendimento de que "a educação se tornou um bem de consumo extremamente rentável para o setor privado, o que justifica tamanho interesse do capital na multiplicação de oportunidades de estudos". A educação é um meio de potencializar o capital humano para o trabalho, dessa forma o mercado de oferta de educação se torna um negócio lucrativo para o setor privado, multiplicam-se as oportunidades para formação de uma mão de obra necessária e excedente para o capital.

No caso do Sistema $S$, que desde sua criação tem como objetivo formar mão de obra para o mercado de trabalho, os programas de gratuidade para o trabalhador resultam em isenções fiscais. O diferencial da atual política de Educação Profissional é o apoio financeiro recebido do Estado e a possibilidade de expansão da instituição e da oferta de Educação Profissional, agora na modalidade Pronatec. O Senac, por exemplo, desenvolve parcerias locais, entre as quais se destacam as realizadas com prefeituras, governos estaduais, ONGs, empresas e instituições públicas e privadas, voltadas ao fomento da cidadania e ao acesso à educação profissional.

No que se refere à parceria do Governo com o Senac para a execução do Pronatec, o Ministério da Educação aponta que essa parceria tem se dado através da implementação do programa com o nome de Acordo de Gratuidade que, teoricamente, tem o objetivo de 
ampliar, progressivamente, a aplicação dos recursos do Senai, do Senac, do Sesc e do Sesi, recebidos da contribuição compulsória que mantém estas instituições. No entanto, além das referidas contribuições compulsórias, há o repasse de verba pública para a execução do Pronatec. Reportagem do Jornal o Globo explicita os recursos adicionais ao informar que o Governo Federal destinou R \$ 899 milhões ao Sistema S para oferta do Pronatec em 2014, assim distribuídos:

\begin{abstract}
O Senai receberá o maior montante, $\mathrm{R} \$ 567,5$ milhões, seguido pelo Senac (R\$ 305,2 milhões), Senat (R\$ 16,3 milhões) e Senar (R\$ 10,8 milhões). O Pronatec foi criado em 2011 pelo governo federal com o objetivo de ampliar a oferta de cursos de educação profissional e tecnológica. (O GLOBO, 2014)
\end{abstract}

Sob o discurso da democratização do acesso e qualificação profissional, o Governo Federal repassa dinheiro público para atender a formação para o mercado de trabalho, no entanto, Leher em entrevista à EPSJV/Fiocruz alerta para a possível privatização da educação a partir dessas políticas de financiamento de serviço público em instituições de caráter privado:

Leher contesta também a ideia de que o financiamento da educação privada é emergencial e está acontecendo em concomitância a um fortalecimento da rede pública. [...] "Estamos azeitando a máquina pública para operar a expansão privada", conclui, chamando a atenção ainda para o fato de que, hoje, o privado que opera na educação não é mais, prioritariamente, composto por instituições familiares que, segundo ele, às vezes mantinham algum "resquício de princípio acadêmico": "Hoje é briga de cachorro grande: lidamos com fundos de investimentos estrangeiros. As instituições passam por processos de aquisição por grandes corporações que estão na bolsa de valores e, portanto, precisam valorizar suas ações". (EPSJV/FIOCRUZ, 2014).

O governo federal tem sido um forte incentivador dessas políticas, principalmente no âmbito da Educação Profissional, com políticas de financiamento estudantil para formação dos jovens e financiamento para as empresas qualificar sua mão de obra. $\mathrm{O}$ Pronatec no contexto de promoção de políticas públicas da Educação Profissional pouco possibilita redução da desigualdade social, vez que, é uma política de formação do trabalhador para um mercado de trabalho, que por si já é excludente, pois não absorve o contingente de trabalhadores qualificados ou não qualificados, a própria lógica do capital é excludente, portanto, a Educação que se destina a esse modelo de sociedade não se desvincula dessa perspectiva. Além disso, o financiamento do Pronatec pelo governo na iniciativa privada viabiliza a mercantilização da Educação enquanto mercadoria e não como um direito do cidadão e um dever do Estado. O Pronatec integra várias ações que buscam articular a expansão da Educação Profissional, mas evidenciamos nesta pesquisa as ações relacionadas a promoção de cursos técnicos por instituições privadas e a oferta de bolsa-formação.

Ações integrantes do Pronatec (IPEA, 2014, p. 34)

Educação: Teoria e Prática/ Rio Claro/ Vol. 25, n.50/ p. 562-575/ Set.-Dez. 2015. 


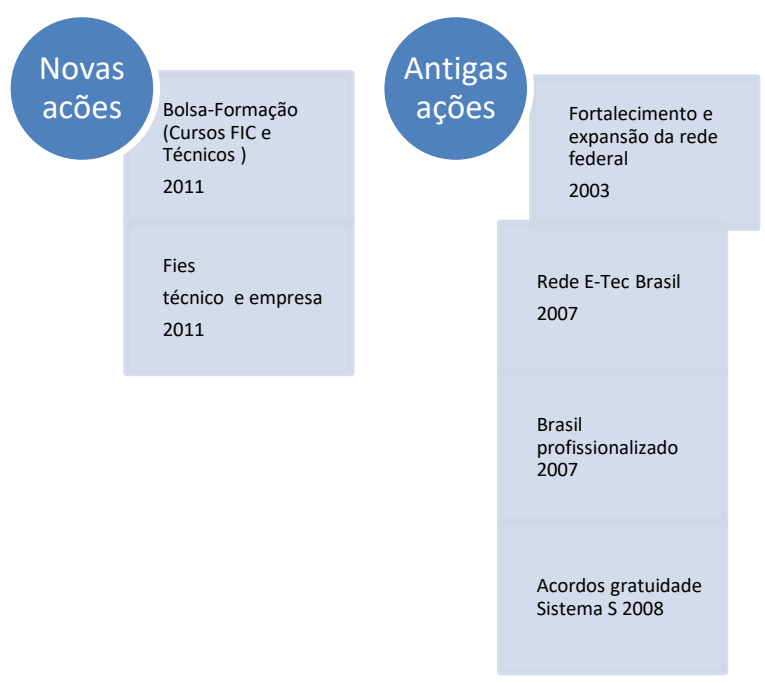

Podemos observar que a expansão da Rede de Educação Profissional e tecnológica é apenas uma ação que integra o Pronatec. Porém a novidade do Pronatec é a Bolsa- Formação e o Fies Técnico e empresa, alvos de bastante críticas por se tornar uma possibilidade de privatização do ensino técnico ao se articular com empresas e o Sistema S, que recebem recursos públicos para executar o programa. Esta perspectiva faz parte de um conjunto de orientação do Banco Mundial para que a Educação Profisisonal fosse gerida por empregadores e outros financiadores privados interessados, abrindo espaço para a privatização.

Estas orientações foram formuladas e aplicadas mais intensamente na década de 1990, no entanto, atualmente repercutem nas políticas de educação profissional, e permeia a proposta do Pronatec, que se articula com Instituições de Ensino Superior Privadas, Sistema S, e demais segmentos empresariais para ofertar cursos técnicos, com o discurso de qualificação profisisonal para a inserção no mundo do trabalho. Para Kuenzer (2001, p.66) isso se dá através "da articulação com a políticas nacionais neoliberais orquestradas pelo Banco Mundial por meio do exercício de sua grande missão: reduzir a pobreza de forma sustentada nos países em desenvolvimento, o que vale dizer, proteger o mundo para os ricos, da destruição que fazem os pobres"

Dentro do padrão de consumo e produção capitalista o Estado tem promovido políticas públicas para esse modelo de educação, pois tem se mostrado viável ao "desenvolvimento econômico", minimamente no que concerne oferecer condições básicas aos trabalhadores para qualificar-se. De acordo com o Ipea $(2014$, p. 28) pode-se afirmar que a Lei $\mathrm{n}^{\mathrm{o}} 12.513$, de 26 de outubro de 2011, que trata do Pronatec, veio atender a um anseio dos trabalhadores pobres e a satisfazer uma necessidade da estrutura produtora de bens e serviços do país.

\section{CONCLUSÃO}


O debate entre o público e o privado na Educação profissional permeia as políticas de acesso ao ensino técnico que tem sido promovidas na modalidade de PRONATEC. Sob a falácia da democratização do acesso à Educação, o Governo realiza parceria com a iniciativa privada para a promoção da oferta de educação, tanto no âmbito da Educação Profissional e em outras modalidades, como o Ensino Superior. Essa perspectiva de oferta da educação em que o público se confunde com o privado, estrategicamente, se apresenta como uma expansão de instituições privadas através da realização de programas para um público de baixa renda com o dinheiro público.

Isto se configura como um financiamento da iniciativa privada pelo Governo. Dinheiro público gerido por instituições privadas que irão expandir seu mercado na oferta de cursos e programas. Na prática surge um mercado promissor de educação que possibilita o lucro dessas empresas de serviço educacional. Uma nova modalidade de empresariado que se articula com a esfera pública para expandir seus negócios. A educação no rol da privatização e mercantilização de um serviço que deveria ser direito do cidadão e dever do Estado.

A demanda e oferta dos cursos técnicos demonstram a necessidade que os trabalhadores têm para se qualificar e procurar uma formação que possibilite a inserção no mercado de trabalho. Ao mesmo tempo, a iniciativa privada, no âmbito da educação, tem conseguido compreender essa tendência para a ampliação do seu mercado de oferta de cursos, principalmente, com os cursos técnicos.

As políticas de Educação profissional se baseiam na proposta de promover desenvolvimento social e econômico e contribuir para a qualificação do trabalhador como uma resposta às transformações do mercado e da produção. Nesse contexto, o Pronatec se apresenta como um programa que tenta integrar ações para expansão da rede de educação profissional e possibilitar a inserção no mundo do trabalho. Direcionada a parcela mais pauperizada da sociedade, carrega em sua construção a histórica dualidade entre ensino técnico e propedêutico.

Esta dualidade estrutural, presente na formulação da política de educação profissional, arrefece a construção de um sistema de educação unitário, que vise articular uma formação humana integral do sujeito com a qualificação profissional. O Pronatec no âmbito dessa política reforça essa contradição. No modelo da sociabilidade contemporânea essa dualidade funciona como uma hierarquização do saber escolar e institucional. Pois dicotomiza a oferta de ensino para parcela da população em busca de cursos e treinamentos aligeirados para se inserir no mercado de trabalho, e aos que tem acesso a um processo de escolarização regular e mais amplo.

\section{Referências}

BRASIL. Objetivos e iniciativas do PRONATEC. Disponível em: http://pronatec.mec.gov.br/institucional-90037/objetivos-e-iniciativas. Acesso em: 14 Jun.2014 
BRASIL, Ministério da Educação. Decreto No 5.154 de 23 de julho de 2004. Disponível em:http://www.planalto.gov.br/ccivil_03/_ato2004-2006/2004/decreto/d5154.htm. Acesso em: 20 de dez. 2014.

BRASIL, Ministério da Educação. Governo e Sistema $\mathbf{S}$ fecham acordo. Disponível em: http://portal.mec.gov.br/index.php?option=com_content\&task=view\&id=10909. Acesso em: 14 jun.2014

BRASIL, Ministério da Educação. Programa Nacional de Acesso ao Ensino Técnico e Emprego (PRONATEC): Lei No 12.513, de 26 de Outubro de 2011. Disponível em:<http://www.planalto.gov.br/ccivil_03/_ato2011-2014/2011/lei/112513.htm>. Acesso em: 10. jun. 2014.

BRASIL, Ministério da Educação. Decreto no 2.208, de 17 de abril de 1997. Disponível em <http://www.planalto.gov.br/ccivil_03/decreto/D2208.htm> Acesso em 20 ag.2014

BRASIL, Ministério da Educação. Políticas públicas para a Educação Profissional e Tecnológica. Brasília, 2004. Disponível em:

http://portal.mec.gov.br/setec/arquivos/pdf/p_publicas.pdf. Acesso em: 27 de nov. de 2014.

BRASIL, Ministério da Educação. Secretaria de Educação Profissional e Tecnológica.

Disponível em: http://portal.mec.gov.br/setec/arquivos/pdf/p_publicas.pdf. Acesso em 05 de jan. de 2015.

BRASIL, Ministério da Educação. Catálogo Nacional de Cursos Técnicos. Disponível em: < http://pronatec.mec.gov.br/cnct/apresentacao.php>. Acesso: 10 Jan. 2015

CNTE, Revista Semestral da Escola da Confederação Nacional dos Trabalhadores em Educação Retratos da Escola. Ensino médio e Educação Profissional. v.5, n. 8, jan./jun. 2011 - Brasília, CNTE.

EPSJV/FIOCRUZ. O privado na educação: Brasil ganha maior empresa de educação do mundo. Disponível em:

http://www.epsjv.fiocruz.br/index.php?Area=Noticia\&Num=875. Acesso em: 01 jun.2014

GENTILI, Pablo. Educar Para o Desemprego: a desintegração da promessa integradora. In: FRIGOTTO, Gaudêncio (Org.). Educação e Crise do Trabalho: perspectivas de final de século. Petrópolis(RJ): Vozes, 1998.

GUIMARÃES, Cátia; JÚNIA, Raquel. O privado na educação: Brasil ganha maior empresa de educação do mundo. EPSJV/FIOCRUZ. Disponível em: http://www.epsjv.fiocruz.br/index.php?Area=Noticia\&Num=875. Acesso em: 01 jun. 2014

IPEA, Instituto de Pesquisa Econômica Aplicada. Pronatec: múltiplos arranjos e ações para ampliar o acesso à educação profissional. Brasília : Rio de Janeiro : Ipea , 2014. Educação: Teoria e Prática/ Rio Claro/ Vol. 25, n.50/ p. 562-575/ Set.-Dez. 2015. 
O'CONNOR, James. USA: a crise do Estado capitalista. Rio de Janeiro, Paz e Terra, 1997.

EPSJV/FIOCRUZ. Pronatec: público e privado na educação profissional. Disponível em:http://www.epsjv.fiocruz.br/index.php?Area=Noticia\&Num=507. Acesso em: 01 jun. 2014

KUENZER, Acacia. Ensino Médio e Profissional: As políticas do Estado Neoliberal. 3 ed. São Paulo, Cortez, 2001.

OLIVEIRA, Elenilce Gomes de (Orgs.). Educação profissional: Análise contextualizada. Fortaleza: CEFET-CE, 2005.

O GLOBO. Governo destina R $\mathbf{8 9 9}$ milhões ao Sistema S para oferta de cursos do Pronatec. Disponível em: http://oglobo.globo.com/sociedade/educacao/governo-destina899-milhoes-ao-sistema-para-oferta-de-cursos-do-pronatec-11449345. Publicado em 30/01/2014. Acesso em 14 jun.2014

PIAUÍ. Relatório Analítico da Superintendência de Ensino-SEDUC. Teresina-PI: 2013. PAIVA, Vanilda. Qualificação, crise do trabalho assalariado e exclusão social. In: A cidadania negada: políticas de exclusão na educação e no trabalho. Pablo Gentili e Gaudêncio Frigotto (orgs). 3 ed. São Paulo: Cortez; 2002.

PARO, Vitor Henrique. Parem de preparar para o trabalho!!! - Reflexões acerca dos efeitos do neoliberalismo sobre a gestão e o papel da escola básica. In: Escritos sobre educação. São Paulo: Xamã, 2001.

SEVERINO, Antonio Joaquim. Metodologia do trabalho científico. 23 ed. rev. e atual. 5 reimpressao. São Paulo Cortez, 2010.

SENAC. Pronatec. Disponível em: http://www.senac.br/programas/pronatec.aspx. Acesso em: 16 jun. 2014

SOUSA, Antonia de Abreu. Política Pública para a Educação Profissional e Tecnológica no Brasil. Fortaleza, Edições UFC, 2011

TEODORO, Maria Cecília Máximo. Capitalismo, trabalho e educação em tempos de neoliberalismo: diagnóstico e críticas. Disponível em: http://www.publicadireito.com.br/artigos/?cod=6ef80bb237adf4b6. Acesso em: 15 jun. 2014 
Recebido em: 30/03/2015

Aprovado para publicação em: 09/11/2015

Publicado em: 22/12/2015 